\title{
ОЦЕНКА СТЕПЕНИ ИЗВЛЕЧЕНИЯ И СВОЙСТВ ПЕКТИНА ЛОПУХА ARCTIUM LAPPA L. ПРИ ЭКСТРАГИРОВАНИИ ЦИТРАТОМ АММОНИЯ
}

\author{
(ㄱ) О.В. Лепилова", С.А. Кокиаров \\ Институт химии растворов им. Г.А. Крестова РАН, ул. Академическая, 1, \\ Иваново, 153045 (Россия), e-mail: lov@isc-ras.ru
}

Сопоставлена эффективность экстракции пектиновых веществ из надземной массы лопуха Arctium Lappa L. растворами цитрата аммония $(1 \%)$, соляной $(1,5 \%)$ и щавелевой $(0,25 \%)$ кислот, смеси $0,5 \%$ растворов $\mathrm{H}_{2} \mathrm{C}_{2} \mathrm{O}_{4}$ и $\left(\mathrm{NH}_{4}\right)_{2} \mathrm{C}_{2} \mathrm{O}_{4}$. Выявлены технологические преимущества применения цитрата аммония в качестве эффективного экстрагирующего агента для выделения пектиновых веществ из растительного сырья. Отмечен высокий выход продукта: по количеству выделенного пектина результат сопоставим с максимальным для контрольных сред уровнем, достигнутым при экстракции раствором соляной кислоты. По совокупности физико-химических свойств продукт близок и даже превосходит некоторые показатели аналогов, извлекаемых растворами щавелевой кислоты и ее смеси с оксалатом аммония. Использование цитрата аммония в качестве экстрагирующего агента обеспечивает получение продукта с максимальным содержанием уронидов при минимальной массовой доле балластных веществ. Величина кинематической вязкости $1 \%$ гидрогелей, выделенного пектина, сопоставима с результатом для контрольных органических сред и превышает в 1,4 раза уровень показателя для продукта экстракции раствором соляной кислоты. Содержание свободных и метоксилированных карбоксильных групп пектиновых веществ, извлекаемых цитратом аммония, составляет соответственно 6,3 и $5,4 \%$.

Ключевые слова: лопух Arctium Lappa L., пектин, экстракция, цитрат аммония.

\section{Введение}

Пектин входит в состав структурных элементов клеточной ткани практически всех наземных растений [1]. В качестве источников пектинов могут быть использованы применяемые в фитотерапии лекарственные травы, например, лопух большой Arctium Lappa L.

Выбор экстрагента для выделения пектина обуславливает различие физико-химических характеристик продукта $[1,2]$. В частности, использование воды в качестве экстрагирующего агента позволяет выделить только водорастворимые фракции пектина [2]. Применение растворов минеральных кислот, в частности соляной, обеспечивает повышение полноты выхода пектина. При этом существует вероятность его гидролитической деструкции, повышающаяся с ростом кислотности среды. Более щадящие условия извлечения создаются при использовании органических реагентов, например, щавелевой кислоты, оксалата аммония или их смеси. В этом случае снижение выхода продукта компенсируется улучшением его качественных характеристик. При спектрофотометрической оценке содержания полиуронидов в растительной биомассе в качестве экстрагента используют 1\%-ный раствор цитрата аммония [3]. Данный раствор имеет показатель рН, близкий к нейтральному, что может стать благоприятным фактором для повышения растворимости пектина в результате диссоциации карбоксильных групп, подавляемой в кислотной среде. Однако в научной литературе отсутствует информация о физико-химических характеристиках пектина, выделенного из растительного сырья с использованием цитрата аммония. В связи с этим цель работы состояла в сравнительной оценке степени

Лепилова Ольга Владимировна - научный сотрудник, кандидат технических наук, тел./факс: (4932) 33-62-61, e-mail: lov@isc-ras.ru

Кокшаров Сергей Александрович - заведующий лабораторией, доктор технических наук, профессор, тел./факс: (4932) 33-62-61, e-mail: ksa@isc-ras.ru извлечения пектина из лопуха раствором цитрата аммония, а также сопоставление его физикохимических характеристик относительно аналогов, полученных при использовании ряда известных экстрагентов.

\footnotetext{
* Автор, с которым следует вести переписку.
} 


\section{Экспериментальная часть}

В качестве объекта исследования использована надземная масса зелени лопуха, заготовленная в период цветения. Биомасса высушивалась при комнатной температуре и измельчалась на лабораторной мельнице до размера частиц твердой фазы 0,3-0,5 см. Подготовка травянистой массы проведена в соответствии с методом, описанным в работе [2].

В качестве экстрагентов использованы растворы: I - 1\%-ного цитрата аммония (pH 5,0); II - 1,5\%ной соляной кислоты (pH 0,7); III - 0,25\%-ной щавелевой кислоты (pH 2,0); IV - смесь 0,5\%-ных растворов щавелевой кислоты и оксалата аммония ( $\mathrm{pH} 2,6)$.

Общий гидромодуль экстракции во всех случаях составлял $1: 10$. Выделение пектина из лопуха осуществляли при температуре термостатирования $80{ }^{\circ} \mathrm{C}$ в течение 2 ч при постоянном перемешивании. После отделения биомассы центрифугированием проводили осаждение пектина в супернатанте трехкратным объемом 96\%-ного этилового спирта подкисленного раствором соляной кислоты (5\%). Гелеобразный осадок отфильтровывали через батистовый фильтр с помощью вакуумного водоструйного насоса и промывали 70\%-ным этанолом. Высушенный в сушильном шкафу при $40{ }^{\circ} \mathrm{C}$ продукт завешивали на аналитических весах и рассчитывали количество выделенного пектина $W$.

Для оценки физико-химических свойств препаратов пектина использовали описанные в [1] методы анализа массовой доли балластных веществ, содержания уронидов по карбазоловой реакции, массовой доли свободных $\left(K_{C}\right)$ и метоксилированных (этерифицированных) $\left(K_{\ni}\right)$ карбоксильных групп, степени этерификации пектина $(C Э)$, а также кинематической вязкости $1 \%$ гидрогелей $(\eta)$ [5].

\section{Обсуждение результатов}

Выявлено, что величина показателя $W$ в зависимости от используемой экстракционной системы I-IV составляет соответственно (масс.\%): 18,5; 18,9; 13,9 и 15,3. Результаты анализа качественных характеристик продуктов располагаются в рядах согласно порядку перечисления растворителя I-IV и позволяют дать следующую сравнительную оценку действия циитрата аммония:

массовая доля балластных веществ (масс.\%): 6,0; 7,3; 6,4 и 6,1-минимум;

содержание уронидов (\%): 92; 85; 90 и 91 -максимум;

СЭ (\%): 46,5; 43,2; 46,6 и 45,8, т.е. пектин лопуха не зависимо от вида экстрагента относится к низкоэтерифицированной форме;

$K_{C}(\%): 6,3 ; 7,1 ; 6,5$ и $6,6-$ минимум;

$\kappa_{\ni}(\%): 5,4 ; 5,4 ; 5,7$ и 5,7 - промежуточный уровень между раствором минеральной кислоты и контрольными органическими средами;

$\eta\left(\mathrm{Mм}^{2} / \mathrm{c}\right): 7,2 ; 5,1 ; 7,3$ и 7,2 - значение, сопоставимое с результатом для контрольных органических сред и превышение в 1,4 раза над уровнем показателя для продукта экстракции раствором $\mathrm{HCl}$.

\section{Вblводы}

Подтверждены технологические преимущества применения 1\%-ного раствора цитрата аммония при выделении пектина из биомассы лопуха Arctium Lappa L. Получаемый продукт по совокупности физикохимических свойств близок и даже превосходит некоторые показатели аналогов, извлекаемых растворами щавелевой кислоты и ее смеси с оксалатом аммония. По количеству выделенного пектина результат сопоставим с максимальным для контрольных сред уровнем, достигнутым при экстракции раствором соляной кислоты.

\section{Список литературы}

1. Никитина В.С., Гайнанова Л.Т., Абдуллин М.И., Беспалова А.А. Пектиновые вещества корней лопуха обыкновенного Arctium Lappa L. и корней одуванчика лекарственного Taraxacum Officiale Wigg // Химия растительного сырья. 2012. №2. С. 21-26.

2. Полле А.Я., Оводова Р.Г., Попов С.В. Выделение и общая характеристика полисахаридов из пижмы обыкновенной, мать-и-мачехи и лопуха войлочного // Химия растительного сырья. 1999. №1. С. 33-38.

3. Алеева С.В., Кокшаров С.А. Особенности биохимической мацерации отечественного и импортного льняного сырья: сопоставительный анализ химического строения пектиновых веществ // Химия растительного сырья. 2010. №3. C. 11-16.

4. Аверьянова Е.В., Митрофанов Р.Ю. Пектин. Получение и свойства: методические рекомендации по выполнению лабораторных работ. Бийск, 2006. 44 с.

5. Ефремов А.А., Кондратюк Т.А. Выделение пектина из нетрадиционного растительного сырья и применение его в кондитерском производстве // Химия растительного сырья. 2008. №4. С. 171-176.

\footnotetext{
Поступило в редакиию 21 октября 20142.
} После переработки 9 апреля 2015 г. 
Lepilova O.V., Koksharov S.A. ESTIMATION OF DEGREE OF EXTRACTION AND OF PECTIN PROPERTIES FROM BURDOCK ARCTIUM LAPPA L. AT THE EXTRACTION BY AMMONIUM CITRATE

G.A. Krestov Institute of Solution Chemistry of the Russian Academy of Sciences, Akademicheskaya St., 1, Ivanovo,

153045 (Russia),e-mail: lov@isc-ras.ru

The effectiveness of pectin extraction from grassy aboveground mass of burdock Arctium lappa $\mathrm{L}$. by ammonium citrate $1 \%$, hydrochloric acid $(1,5 \%)$, oxalic acid $(0,25 \%)$, mixture of $0,5 \%$ solutions $\mathrm{H}_{2} \mathrm{C}_{2} \mathrm{O}_{4}$ и $\left(\mathrm{NH}_{4}\right)_{2} \mathrm{C}_{2} \mathrm{O}_{4}$ having been compared. Technological advantages of ammonium citrate application as effective extraction agent for isolation of pectin from plant raw materials having been revealed. The high product yield having been noted: the yield of the isolated pectin is comparable to the maximum level for the control systems, reached at the extraction by the hydrochloric acid solution. According to physical and chemical properties the product is close and even surpasses some rates of the analogues extracted by solutions oxalic acid and its mix with ammonium oxalate. Use of ammonium citrate as extraction agent provides reception of a product with the maximum content of uronide at the minimum of ballast compounds mass pert. The size of kinematic viscosity for the $1 \%$ hydrogels of extracted pectin is comparable to result for control organic systems and exceeds the level of the rate for product extracted by hydrochloric acid solution in 1,4 times. Content of free and methoxylic carboxyl groups of the pectin isolated ammonium citrate amount accordingly 6,3 and 5,4\%.

Keywords: burdock Arctium lappa L., pectin, extraction, ammonium citrate.

\section{References}

1. Nikitina V.S., Gainanova L.T., Abdullin M.I., Bespalova A.A. Khimiia rastitel'nogo syría, 2012, no. 2, pp. 21-26. (in Russ.).

2. Polle A.Ia., Ovodova R.G., Popov S.V. Khimiia rastitel'nogo syr'ia, 1999, no. 1, pp. 33-38. (in Russ.).

3. Aleeva S.V., Koksharov S.A. Khimiia rastitel'nogo syr'ia, 2010, no. 3, pp. 11-16. (in Russ.).

4. Aver'ianova E.V., Mitrofanov R.Iu. Pektin. Poluchenie i svoistva. Metodicheskie rekomendatsii po vypolneniiu laboratornykh rabot. [Pectin. Preparation and Properties. Guidelines for laboratory work]. Biisk, 2006, 44 p. (in Russ.).

5. Efremov A.A., Kondratiuk T.A. Khimiia rastitel'nogo syr'ia, 2008, no. 4, pp. 171-176. (in Russ.).

Received October 21, 2014

Revised April 9, 2015

\footnotetext{
"Corresponding author.
} 
